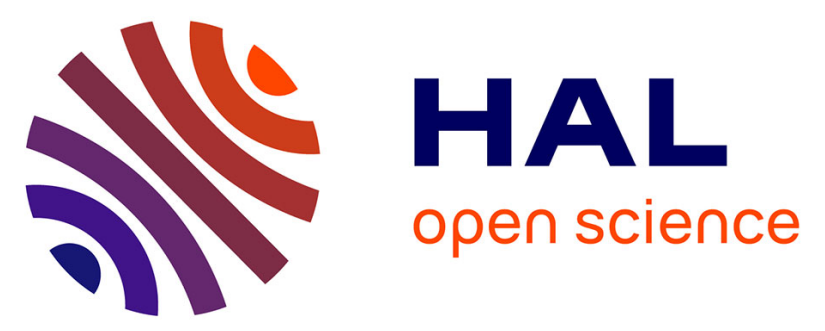

\title{
Vancomycin MIC creep in MRSA blood culture isolates from Germany: a regional problem?
}

J. Kehrmann, M. Kaase, F. Szabados, S. G. Gatermann, J. Buer, P.-M. Rath, J. Steinmann

\section{- To cite this version:}

J. Kehrmann, M. Kaase, F. Szabados, S. G. Gatermann, J. Buer, et al.. Vancomycin MIC creep in MRSA blood culture isolates from Germany: a regional problem?. European Journal of Clinical Microbiology and Infectious Diseases, 2011, 30 (5), pp.677-683. 10.1007/s10096-010-1140-7 . hal00659519

\section{HAL Id: hal-00659519 https://hal.science/hal-00659519}

Submitted on 13 Jan 2012

HAL is a multi-disciplinary open access archive for the deposit and dissemination of scientific research documents, whether they are published or not. The documents may come from teaching and research institutions in France or abroad, or from public or private research centers.
L'archive ouverte pluridisciplinaire HAL, est destinée au dépôt et à la diffusion de documents scientifiques de niveau recherche, publiés ou non, émanant des établissements d'enseignement et de recherche français ou étrangers, des laboratoires publics ou privés. 
Vancomycin MIC creep in MRSA blood culture isolates from Germany: a regional problem?

Jan Kehrmann ${ }^{1}$, Martin Kaase ${ }^{2}$, Florian Szabados ${ }^{2}$, Soeren G. Gatermann ${ }^{2}$, Jan Buer ${ }^{1}$, Peter-Michael Rath ${ }^{1}$, Joerg Steinmann ${ }^{1}$

${ }^{1}$ Institute of Medical Microbiology, University Hospital Essen, University of Duisburg-Essen, Germany

${ }^{2}$ Department of Medical Microbiology, Ruhr University Bochum, Bochum, Germany

Corresponding author:

Joerg Steinmann, MD, Institute of Medical Microbiology, University Hospital Essen

University of Duisburg-Essen, Virchowstr. 179, 45147 Essen

Telephone: + 49-201-72385771

Fax: + 49-201-7235602

E-Mail: joerg.steinmann@uk-essen.de 


\section{$\underline{\text { Abstract }}$}

Purpose: The aim of this study was to assess the vancomycin MIC distribution for MRSA blood culture isolates over a period of six years in Germany.

Methods: The study examined 287 MRSA isolates from blood cultures collected at several hospitals in two German cities between 2004 and 2009. The vancomycin MIC was determined by Etest. Genotypic features of the MRSA strains with vancomycin MIC $\geq 1 \mathrm{mg} / \mathrm{L}$ were determined by semiautomated repetitive-sequencebased polymerase chain reaction.

Results: The range of vancomycin MIC as determined by Etest was 0.25 to $2.0 \mathrm{mg} / \mathrm{L}$. The geometric mean MIC increased by 1.34 -fold in city A over the study period ( $\mathrm{p}<0.05)$, but there was no meaningful change in city B (a 1.09-fold increase, $\mathrm{p}>0.05$ ). Furthermore, in city A a shift in vancomycin MICs occurred as an increase in the percentage of isolates with MIC $\geq 1 \mathrm{mg} / \mathrm{L}$ from period one (2004-2006) to period two (2007-2009) $(p<0.0001)$. Typing results showed that in city A a single clone was predominant (55\% of the creep isolates).

Conclusions: In this study, the creep phenomenon seems to be a regional problem. We suggest that all hospitals should monitor their local status of elevated vancomycin MICs in invasive MRSA isolates.

\section{Keywords: vancomycin MIC creep, MRSA, Etest}




\section{$\underline{\text { Introduction }}$}

Staphylococcus aureus is among the most common pathogens causing hospital- and communityacquired infections and is one of the leading causes of sepsis worldwide. In Europe, S. aureus is the second most common causative organism for bacteraemia [1]. Adequate and early antibiotic therapy is a crucial factor in the prognosis of sepsis [2-4]. The antibiotic treatment of S. aureus infections is complicated by the increasing prevalence of methicillin-resistant S. aureus (MRSA) [1, 5]. Infections caused by MRSA are associated with a higher mortality rate than are those associated with methicillin-susceptible $S$. aureus (MSSA) [6, 7], and they require a longer hospital stay and higher costs. In the United States, nearly half of all S. aureus isolates from patients are MRSA [8], whereas in Germany approximately 20\% of such isolates are MRSA [9].

The first antibiotic agent and today still the gold standard for the treatment of invasive MRSA infections is the glycopeptide vancomycin. The first isolate with reduced vancomycin susceptibility (minimum inhibitory concentration [MIC], $8 \mathrm{mg} / \mathrm{L}$ ) was reported in Japan in 1997 [10]. Only a few strains of vancomycin-resistant $S$. aureus (VRSA) and vancomycin-intermediate S. aureus (VISA) have been reported to exhibit resistance to vancomycin $[11,12]$. Nevertheless, the number of patients for whom vancomycin therapy fails is increasing, even though their $S$. aureus strains have been found to be susceptible to vancomycin in vitro (MIC $\leq 2 \mathrm{mg} / \mathrm{L}$ ) [13-15]. Having analyzed clinical and microbiological data, several groups of researchers have concluded that increasing vancomycin MICs in MRSA are associated with a substantial risk of treatment failure and with increased mortality rates [14-17].

Several studies have demonstrated that the mean vancomycin MIC in MRSA has increased in recent years [18-21], but other studies have not confirmed this finding [22, 23]. The observation that vancomycin MICs are increasing within the susceptible range of MRSA is called the creep phenomenon.

As a result of published reports showing that vancomycin therapy fails for patients who have S. aureus infections with a MIC $\geq 4 \mathrm{mg} / \mathrm{L}$, the Clinical and Laboratory Standards Institute (CLSI) reduced the pre-2006 vancomycin breakpoints from $\leq 4 \mathrm{mg} / \mathrm{L}$ to $\leq 2 \mathrm{mg} / \mathrm{L}$ for susceptible $S$. aureus and from $\geq 32 \mathrm{mg} / \mathrm{L}$ to $\geq 16 \mathrm{mg} / \mathrm{L}$ for resistant S. aureus [24]. Some experts believe that these breakpoints are still too high and that a further reduction is necessary to prevent a higher risk of therapy failure for MRSA creep strains and to anticipate future MIC creep trends [25].

Only a few studies have examined the creep phenomenon in Europe, and to the best of our knowledge no studies have examined the creep phenomenon in Germany. Thus, the aim of this study was to analyze the vancomycin MIC distribution in MRSA blood culture obtained over a period of six years in western Germany. 


\section{Material and methods}

\section{Isolates}

In this study we analyzed MRSA blood culture isolates obtained from patients in several hospitals in two cities of the Ruhr region of North Rhine Westphalia between January 2004 and December 2009. Only one isolate per patient was tested. For those patients with more than one isolate, only the first isolate was analyzed. In all, 133 isolates were collected from a tertiary-care hospital in Essen (city A) and 154 from four secondarycare hospitals in Bochum (city B). The two cities are separated by approximately $15 \mathrm{~km}$. Of the 287 isolates, 44 were collected in 2004, 49 in 2005, 59 in 2006, 54 in 2007, 54 in 2008, and 27 in 2009. All isolates were identified as $S$. aureus by conventional standardized laboratory methods (e.g., growth conditions, morphological criteria, pigment production) and by one of two semiautomated systems: Vitek® 2 (bioMérieux, Nürtingen, Germany) or MicroScan® Walkaway (Siemens, Erlangen, Germany). These same commercial systems were also used for susceptibility testing of oxacillin. Individual isolates were then frozen at $-80^{\circ} \mathrm{C}$ until MIC testing was performed.

\section{Vancomycin MIC analysis}

Vancomycin MIC testing was performed by the Etest method, according to the manufacturer's guidelines. A suspension in saline to the $0.5 \mathrm{McFarland}$ turbidity standard was plated on Mueller-Hinton agar, and Etest strips were applied (AB BIODISK, Solna, Sweden, now distributed by bioMérieux). The plates were incubated at $35^{\circ} \mathrm{C}$ for 24 hours. MIC was interpreted as the zone of inhibition corresponding to a concentration gradient on the Etest strips, according to the manufacturer's guidelines. Quality control was performed with the CLSI-recommended reference strain (ATCC 29213).

\section{Data analysis and statistical methods}

The $\mathrm{MIC}_{50}, \mathrm{MIC}_{90}$, MIC range, and geometric mean MIC were evaluated. All calculations were performed for each year, using only those isolates collected in that calendar year. Non-parametric methods (Spearman correlation and chi-square test) were used to asses MIC trends over 6 years. Statistical significance was defined a priori as $\mathrm{p}<0.05$. Statistical analyses were performed with GraphPad Prism, version 5.02 (GraphPad Software, Inc, San Diego, CA, USA).

\section{Genotyping}


Isolates were typed with the semiautomated repetitive-sequence-based polymerase chain reaction (PCR) DiversiLab system (bioMérieux), according to the manufacturer's instructions. Genomic DNA isolation of MRSA isolates was performed with the Mo Bio Ultra Clean preparation kit (bioMérieux). After DNA extraction, the concentration was quantified with a nanodrop1000 spectrometer (Peqlab, Erlangen, Germany) and software version 3.7.1. Genomic DNA concentrations were adjusted to approximately $25 \mathrm{ng} / \mu \mathrm{L}$ as recommended by the manufacturer. The bacterial DNA was amplified with the DiversiLab Staphylococcus aureus kit (bioMérieux) for DNA fingerprinting. In brief, $25 \mathrm{ng}$ of DNA, $2.0 \mu \mathrm{L}$ of the rep-PCR primer mixture provided with the kits, $0.5 \mu \mathrm{L}$ of AmpliTaq ${ }^{\circledR}$ (Applied Biosystems, Foster City, CA, USA), $2.5 \mu \mathrm{L}$ of 10x PCR buffer (Applied Biosystems), and $18 \mu \mathrm{L}$ of the kit-supplied rep-PCR master mix (MM1) were added, for a total of $25 \mu \mathrm{L}$ per reaction mixture. Thermal cycling parameters were as follows: initial denaturation at $94^{\circ} \mathrm{C}$ for 2 min; 35 cycles of denaturation at $94^{\circ} \mathrm{C}$ for $30 \mathrm{~s}$; annealing at $45^{\circ} \mathrm{C}$ for $30 \mathrm{~s}$; extension at $70^{\circ} \mathrm{C}$ for $90 \mathrm{~s}$; and final extension at $70^{\circ} \mathrm{C}$ for $3 \mathrm{~min}$. Separation and detection of the amplified fragments of various sizes and fluorescence intensities were performed by using the micro-fluid chips of the DiversiLab system and a model B 2100 bioanalyzer (Agilent Technologies, Santa Clara, CA, USA). The results were illustrated with the Web-based DiversiLab software version v.r.3.3.40, which uses the Pearson correlation coefficient and the unweighted-pair group method with arithmetic mean to analyze and determine the genetic similarity of the tested samples. Dendrogram and virtual gel images were automatically generated by the software. Cluster analysis, based on peak height and on the presence and absence of the peaks, was performed with DiversiLab. Percentage similarity for genotyping and discrimination of MRSA isolates with vancomycin MIC $\geq 1 \mathrm{mg} / \mathrm{L}$ was set at a cut-off of $96 \%$. 


\section{Results}

This study analyzed a total of 287 blood culture isolates collected from 287 patients in two German cities over a period of six years between 2004 and 2009. All MRSA isolates from both cities were tested as vancomycin-susceptible in vitro. The vancomycin MIC ranged from 0.25 to $2.0 \mathrm{mg} / \mathrm{L}$ (Table $1 \mathrm{~A}$ and $1 \mathrm{~B}$ ). For the isolates from city A, the geometric mean vancomycin MIC increased by 1.34 -fold during the study period: from $0.59 \mathrm{mg} / \mathrm{L}$ in 2004 to $0.79 \mathrm{mg} / \mathrm{L}$ in $2009(\mathrm{p}=0.042)$ (Figure 1A). In contrast, the geometric mean vancomycin MIC for the isolates from city B exhibited only a slight increase (1.09-fold; not statistically significant) during the study period: from $0.47 \mathrm{mg} / \mathrm{L}$ in 2004 to $0.51 \mathrm{mg} / \mathrm{L}$ in 2009 ( $p>0.05$ ) (Figure 1B). For the isolates from city $\mathrm{A}$, the percentile markers for $\mathrm{MIC}_{50}$ increased from $0.5 \mathrm{mg} / \mathrm{L}$ to $0.75 \mathrm{mg} / \mathrm{L}$, and those for $\mathrm{MIC}_{90}$ increased from $0.75 \mathrm{mg} / \mathrm{L}$ to $1.0 \mathrm{mg} / \mathrm{L}$. For city $\mathrm{B}$, in contrast, the percentile markers for $\mathrm{MIC}_{50}(0.5$ $\mathrm{mg} / \mathrm{L})$ and $\mathrm{MIC}_{90}(0.75 \mathrm{mg} / \mathrm{L})$ remained unchanged during the study period. The increase in the mean vancomycin MIC in city A was primarily due to a significant increase in the percentage of isolates with a MIC $\geq 1 \mathrm{mg} / \mathrm{L}$ from period one (2004-2006) to period two (2007-2009) $(\mathrm{p}<0.0001)$. The fraction of these isolates with a MIC $\geq 1 \mathrm{mg} / \mathrm{L}$ increased from $6.7 \%$ in 2004 to $20.8 \%$ in 2007 and $35.7 \%$ in 2009 , whereas only two of the isolates from city B had a vancomycin $\mathrm{MIC} \geq 1 \mathrm{mg} / \mathrm{L}$

All MRSA isolates with a vancomycin MIC $\geq 1 \mathrm{mg} / \mathrm{L}$ were typed with the semiautomatic sequencebased PCR DiversiLab system. This testing included 18 MRSA isolates from city A and two isolates from city B. Eleven of these 20 isolates, all from city A, exhibited a similarity of $96 \%$ or higher, a finding indicating a clonal evolution in these isolates; this evolution involved $55 \%$ of all isolates with a MIC $\geq 1 \mathrm{mg} / \mathrm{L}$ (Figure 2). The first of these isolates was obtained from a patient treated in 2004; the last, from a patient treated in 2009. The isolates were obtained from patients hospitalized in different clinical departments. The two isolates from city B did not belong to this clonal cluster. 


\section{$\underline{\text { Discussion }}$}

This study analyzed the vancomycin MIC of 287 MRSA blood culture isolates collected in several hospitals in two German cities between 2004 and 2009. The vancomycin MICs for MRSA blood culture isolates from city A increased significantly over the study period, but there was no significant increase in vancomycin MICs for MRSA blood culture isolates from city B. To the best of our knowledge, this study is the first to analyze the existence of a vancomycin creep phenomenon for MRSA in Germany. Typing of the isolates with a vancomycin MIC $\geq 1 \mathrm{mg} / \mathrm{L}$ showed that a single clone was predominant and was responsible for $55 \%$ of these isolates.

The interest in analyzing vancomycin MICs is not only originated from concern that a further creep could shift MICs into the non-susceptible zone. There have been several reports of treatment failure against vancomycin-susceptible isolates [14-16, 26-28]. Patients with a MRSA bloodstream infection with an elevated vancomycin MIC ( $\geq 1.5 \mathrm{mg} / \mathrm{L})$ were reported to have a longer duration of bacteraemia, a higher probability of recurrent bacteraemia within 60 days after vancomycin discontinuation, and a longer hospital stay [26]. The likelihood of treatment success was significantly lower for patients with MRSA isolates with a vancomycin MIC of 1 to $2 \mathrm{mg} / \mathrm{L}$ than for patients with a vancomycin MIC $\leq 0.5 \mathrm{mg} / \mathrm{L}$ [27]. Treatment with vancomycin was successful for $55.6 \%$ of the patients with a vancomycin MIC $\leq 0.5 \mathrm{mg} / \mathrm{L}$ but for only $9.5 \%$ of those with a vancomycin MIC of 1 to $2 \mathrm{mg} / \mathrm{L}$ [27].

The phenomenon of an increasing vancomycin MIC for MRSA has been demonstrated by several single-centre studies in the United States [18-20] and by a study from the health care region of Hong Kong [21]. An examination of the extent of the vancomycin creep found a more than three-fold increase in the proportion of strains with $\mathrm{MIC}=1 \mathrm{mg} / \mathrm{L}[18,19]$. During the same period, the proportion of strains with $\mathrm{MIC} \leq 0.5 \mathrm{mg} / \mathrm{L}$ showed a decrease of a similar proportion [19]. Wang et al. found only a small increase in the proportion of strains with MIC $\geq 2.0 \mathrm{mg} / \mathrm{L}$ [19], and Steinkraus et al. found no non-susceptible strains [18]. Our findings regarding the isolates from city A agree with these results: we found an increasing proportion of strains with vancomycin MICs $\geq 1 \mathrm{mg} / \mathrm{L}$ and a decreasing proportion of strains with MICs $\leq 0.5 \mathrm{mg} / \mathrm{L}$; in addition, we found no intermediate strains (MIC $>2 \mathrm{mg} / \mathrm{L}$ and $\leq 4 \mathrm{mg} / \mathrm{L}$ ). In contrast to the findings of reported studies, we also found increasing percentile markers of $\mathrm{MIC}_{50}$ and $\mathrm{MIC}_{90}$ for the isolates from city $\mathrm{A}$.

The isolates from city B did not show a relevant increase in vancomycin mean MIC or in $\mathrm{MIC}_{50}$ or $\mathrm{MIC}_{90}$. These results are consistent with those of a multi-centre study of nine US medical centres that found no increase in vancomycin MIC for all sites between 1999 and 2006. Vancomycin MIC increased at three sites but decreased at three other sites [22]. A survey from Spain found no MIC creep in MSSA or MRSA isolates from 
2002 to 2006 [23]. Also, the SENTRY Antimicrobial Surveillance Program database for the years 1998 to 2003 , which included 35,458 MSSA and MRSA isolates, found no change in vancomycin MIC over the study period [28].

However, the question of why a creep phenomenon has been detected at some centres but not all has not yet been sufficiently answered. Because of the heterogeneity of the studies performed to date, a direct comparison is difficult. The studies differ in the periods analyzed, the methods used for susceptibility testing (Etest vs. broth dilution), and the type of isolates analyzed (MRSA vs. MSSA and blood culture vs. all clinical isolates).

The two methods primarily used in previously published to analyze the vancomycin MIC in MSSA and MRSA, Etest and broth dilution, yielded different results. The findings generated by Etest were a single two-fold dilution higher than those generated by CLSI broth dilution [30]. The Etest method is more sensitive in detecting small vancomycin MIC changes than the broth dilution method, provided that the traditional two-fold dilution MIC testing is performed. The studies that did not find a vancomycin MIC creep used primarily the broth dilution method, whereas most studies that did find a vancomycin MIC creep used the Etest method [18-21]. The Etest method appears to be more reliable than the broth dilution and semiautomated systems in correlating treatment response and an elevated MIC $>1 \mathrm{mg} / \mathrm{L}[31]$.

Unfortunately, most studies describing a vancomycin MIC creep phenomenon did not analyze the strains with a high vancomycin MIC by molecular typing methods to determine whether the creep was due to a dissemination of clonal MRSA clusters. Recently, Ho et al. reported their finding of an increased percentage of clones that lead to a vancomycin creep among MRSA blood culture isolates in Hong Kong [21]. We used molecular typing by DiversiLab and found that a single predominant clone accounted for $55 \%$ of the isolates with a vancomycin $\mathrm{MIC} \geq 1 \mathrm{mg} / \mathrm{L}$. Interestingly, a recent molecular-epidemiological study of the geographic distribution of invasive MSSA and MRSA isolates in Europe showed a restriction on only a few predominant MRSA clones that clustered regionally [32]. In that study, multilocus sequence typing demonstrated that, in the analyzed regions in Germany, two MRSA spa types were responsible for more than $60 \%$ of invasive isolates.

Because existing findings indicate that the probability of therapy failure is higher for invasive MRSA infections caused by strains with an increased vancomycin MIC, and because a creep phenomenon appears to exist in some regions, we suggest that every medical centre should examine the local situation of vancomycin MICs in MRSA isolates from blood cultures by Etest. Furthermore, if a vancomycin MIC creep is found in 
MRSA strains in the patient population of a medical centre, the centre's decision-makers should include in their discussions about the appropriate therapy the main risk factors associated with the patients' acquisition of MRSA with elevated vancomycin MICs. Those factors are exposure to vancomycin during the past month and the collection of the isolate while the patient is in an ICU [33]. Increasing the dosage of vancomycin given to MRSA patients with elevated vancomycin MICs does not seem to improve outcome; instead, it may impair renal function, particularly when patients are concurrently taking a nephrotoxic medication [29]. For invasive MRSA infections with strains that have an elevated vancomycin MIC, physicians might consider an alternative therapy, such as daptomycin or linezolid, both of which have been reported to exhibit high in vitro activity $[34,35]$ and to be effective in treating invasive MRSA infections in clinical trials [35-37].

This study is limited by the fact that it examined MRSA blood culture isolates from only two cities in the Ruhr area; therefore, the findings may not be representative of all of Germany. Another limitation is the lack of clinical information about the outcome of the patients. Nevertheless, this is not a clinical trial but is rather an epidemiological study analyzing the vancomycin MIC.

In summary, this study compared the vancomycin MIC distribution in two German cities. A vancomycin MIC creep phenomenon was detected at one site on the basis of a significant increase in the number of isolates with a MIC of $1 \mathrm{mg} / \mathrm{L}$ or higher. Typing showed that a single clone was predominant for $55 \%$ of these isolates. The vancomycin MIC creep phenomenon seems to be a regional problem and we suggest that all hospitals should monitor their local status of elevated vancomycin MICs in invasive MRSA isolates. More studies will be necessary to verify our observation and to confirm the situation in the entire country of Germany. 


\section{$\underline{\text { Acknowledgment }}$}

We thank Melanie Wilmes and Dirk Schmidt for their excellent technical assistance. 


\section{Reference List}

1. Biedenbach DJ, Moet GJ, Jones RN (2004) Occurrence and antimicrobial resistance pattern comparisons among bloodstream infection isolates from the SENTRY Antimicrobial Surveillance Program (19972002). Diagn Microbiol Infect Dis 50: 59-69

2. Soriano A, Martinez JA, Mensa J, Marco F, Almela M, Moreno-Martinez A, Sánchez F, Muñoz I, Jiménez de Anta MT, Soriano E (2000) Pathogenic significance of methicillin resistance for patients with Staphylococcus aureus bacteremia. Clin Infect Dis 30: 368-373

3. Ibrahim EH, Sherman G, Ward S, Fraser VJ, Kollef MH (2000) The influence of inadequate antimicrobial treatment of bloodstream infections on patient outcomes in the ICU setting. Chest 118: 146-155

4. Kumar A, Roberts D, Wood KE, Light B, Parrillo JE, Sharma S, Suppes R, Feinstein D, Zanotti S, Taiberg L, Gurka D, Kumar A, Cheang M (2006) Duration of hypotension before initiation of effective antimicrobial therapy is the critical determinant of survival in human septic shock. Crit Care Med 34: $1589-1596$

5. Tiemersma EW, Monnet DL, Bruinsma N, Skov R, Monen JC, Grundmann H (2005) Staphylococcus aureus bacteremia, Europe. Emerg Infect Dis 11: 1798-1799

6. Cosgrove SE, Sakoulas G, Perencevich EN, Schwaber MJ, Karchmer AW, Carmeli Y (2003) Comparison of mortality associated with methicillin-resistant and methicillin-susceptible Staphylococcus aureus bacteremia: a meta-analysis. Clin Infect Dis 36: 53-59

7. Whitby M, McLaws ML, Berry G (2001) Risk of death from methicillin-resistant Staphylococcus aureus bacteraemia: a meta-analysis. Med J Aust 175: 264-267

8. Styers D, Sheehan DJ, Hogan P, Sahm DF (2006) Laboratory-based surveillance of current antimicrobial resistance patterns and trends among Staphylococcus aureus: 2005 status in the United States. Ann Clin Microbiol Antimicrob 5: 2

9. Kresken M., Hafner D., Schmitz F.-J., Wichelhaus T.A. für die Studiengruppe. Resistenzsituation bei klinisch wichtigen Infektionserregern gegenüberAntibiotika in Deutschland und im mitteleuropäischen Raum. Bericht über die Ergebnisse einer multizentrischen Studie der Arbeitsgemeinschaft Empfindlichkeitsprüfungen \& Resistenz der Paul-Ehrlich-Gesellschaft für Chemotherapie e.V. aus dem Jahre 2007. Antiinfective Intelligence, Rheinbach, 2009

10. Hiramatsu K, Hanaki H, Ino T, Yabuta K, Oguri T, Tenover FC (1997) Methicillin-resistant Staphylococcus aureus clinical strain with reduced vancomycin susceptibility. J Antimicrob Chemother 40: $135-136$ 
11. Tenover FC, Lancaster MV, Hill BC, Steward CD, Stocker SA, Hancock GA, O'Hara CM, McAllister SK, Clark NC, Hiramatsu K (1998) Characterization of staphylococci with reduced susceptibilities to vancomycin and other glycopeptides. J Clin Microbiol 36: 1020-1027

12. Van Griethuysen A, Van 't Veen A, Buiting A, Walsh T, Kluytmans J (2003) High percentage of methicillin-resistant Staphylococcus aureus isolates with reduced susceptibility to glycopeptides in The Netherlands. J Clin Microbiol 41: 2487-2491

13. Moise PA, Schentag JJ (2000) Vancomycin treatment failures in Staphylococcus aureus lower respiratory tract infections. Int J Antimicrob Agents 16 Suppl 1: S31-S34

14. Soriano A, Marco F, Martinez JA, Pisos E, Almela M, Dimova VP, Alamo D, Ortega M, Lopez J, Mensa $\mathbf{J}$ (2008) Influence of vancomycin minimum inhibitory concentration on the treatment of methicillinresistant Staphylococcus aureus bacteremia. Clin Infect Dis 46: 193-200

15. Howden BP, Ward PB, Charles PG, Korman TM, Fuller A, du Cros P, Grabsch EA, Roberts SA, Robson J, Read K, Bak N, Hurley J, Johnson PD, Morris AJ, Mayall BC, Grayson ML (2004) Treatment outcomes for serious infections caused by methicillin-resistant Staphylococcus aureus with reduced vancomycin susceptibility. Clin Infect Dis 38: 521-528

16. Charles PG, Ward PB, Johnson PD, Howden BP, Grayson ML (2004) Clinical features associated with bacteremia due to heterogeneous vancomycin-intermediate Staphylococcus aureus. Clin Infect Dis 38: $448-451$

17. Wang JL, Wang JT, Sheng WH, Chen YC, Chang SC (2010) Nosocomial methicillin-resistant Staphylococcus aureus (MRSA) bacteremia in Taiwan: mortality analyses and the impact of vancomycin, $\mathrm{MIC}=2 \mathrm{mg} / \mathrm{L}$, by the broth microdilution method. BMC Infect Dis 10: 159

18. Steinkraus G, White R, Friedrich L (2007) Vancomycin MIC creep in non-vancomycin-intermediate Staphylococcus aureus (VISA), vancomycin-susceptible clinical methicillin-resistant S. aureus (MRSA) blood isolates from 2001-05. J Antimicrob Chemother 60: 788-794

19. Wang G, Hindler JF, Ward KW, Bruckner DA (2006) Increased vancomycin MICs for Staphylococcus aureus clinical isolates from a university hospital during a 5-year period. J Clin Microbiol 44: 3883-3886

20. Rybak MJ, Leonard SN, Rossi KL, Cheung CM, Sader HS, Jones RN (2008) Characterization of vancomycin-heteroresistant Staphylococcus aureus from the metropolitan area of Detroit, Michigan, over a 22-year period (1986 to 2007). J Clin Microbiol 46: 2950-2954

21. Ho PL, Lo PY, Chow KH, Lau EH, Lai EL, Cheng VC, Kao RY (2010) Vancomycin MIC creep in MRSA isolates from 1997 to 2008 in a healthcare region in Hong Kong. J Infect 60: 140-145 
22. Sader HS, Fey PD, Limaye AP, Madinger N, Pankey G, Rahal J, Rybak MJ, Snydman DR, Steed LL, Waites K, Jones RN (2009) Evaluation of vancomycin and daptomycin potency trends (MIC creep) against methicillin-resistant Staphylococcus aureus isolates collected in nine U.S. medical centers from 2002 to 2006. Antimicrob Agents Chemother 53: 4127-4132

23. Alós JI, Garcia-Cañas A, Garcia-Hierro P, Rodriguez-Salvanés F (2008) Vancomycin MICs did not creep in Staphylococcus aureus isolates from 2002 to 2006 in a setting with low vancomycin usage. J Antimicrob Chemother 62: 773-775

24. Tenover FC, Moellering RC Jr (2007) The rationale for revising the Clinical and Laboratory Standards Institute vancomycin minimal inhibitory concentration interpretive criteria for Staphylococcus aureus. Clin Infect Dis 44: 1208-1215

25. Gould IM (2007) The problem with glycopeptides. Int J Antimicrob Agents 30: 1-3

26. Lodise TP, Graves J, Evans A, Graffunder E, Helmecke M, Lomaestro BM, Stellrecht K (2008) Relationship between vancomycin MIC and failure among patients with methicillin-resistant Staphylococcus aureus bacteremia treated with vancomycin. Antimicrob Agents Chemother 52: 3315 3320

27. Sakoulas G, Moise-Broder PA, Schentag J, Forrest A, Moellering RC Jr, Eliopoulos GM (2004) Relationship of MIC and bactericidal activity to efficacy of vancomycin for treatment of methicillinresistant Staphylococcus aureus bacteremia. J Clin Microbiol 42: 2398-2402

28. Jones RN (2006) Microbiological features of vancomycin in the 21st century: minimum inhibitory concentration creep, bactericidal/static activity, and applied breakpoints to predict clinical outcomes or detect resistant strains. Clin Infect Dis 42 Suppl 1: S13-S24

29. Hidayat LK, Hsu DI, Quist R, Shriner KA, Wong-Beringer A (2006) High-dose vancomycin therapy for methicillin-resistant Staphylococcus aureus infections: efficacy and toxicity. Arch Intern Med 166: 21382144

30. Prakash V, Lewis JS 2nd, Jorgensen JH (2008) Vancomycin MICs for methicillin-resistant Staphylococcus aureus isolates differ based upon the susceptibility test method used. Antimicrob Agents Chemother 52: 4528

31. Hsu DI, Hidayat LK, Quist R, Hindler J, Karlsson A, Yusof A, Wong-Beringer A (2008) Comparison of method-specific vancomycin minimum inhibitory concentration values and their predictability for treatment outcome of meticillin-resistant Staphylococcus aureus (MRSA) infections. Int J Antimicrob Agents 32: 378-385 
32. Grundmann H, Aanensen DM, van den Wijngaard CC, Spratt BG, Harmsen D, Friedrich AW; European Staphylococcal Reference Laboratory Working Group (2010) Geographic distribution of Staphylococcus aureus causing invasive infections in Europe: a molecular-epidemiological analysis. PLoS Med 7: e1000215

33. Lodise TP, Miller CD, Graves J, Evans A, Graffunder E, Helmecke M, Stellrecht K (2008) Predictors of high vancomycin MIC values among patients with methicillin-resistant Staphylococcus aureus bacteraemia. J Antimicrob Chemother 62: 1138-1141

34 LaPlante KL, Rybak MJ (2004) Impact of high-inoculum Staphylococcus aureus on the activities of nafcillin, vancomycin, linezolid, and daptomycin, alone and in combination with gentamicin, in an in vitro pharmacodynamic model. Antimicrob Agents Chemother 48: 4665-4672

35. Sakoulas G, Golan Y, Lamp KC, Friedrich LV, Russo R (2007) Daptomycin in the treatment of bacteremia. Am J Med 120: S21-S27

36. Wunderink RG, Rello J, Cammarata SK, Croos-Dabrera RV, Kollef MH (2003) Linezolid vs vancomycin: analysis of two double-blind studies of patients with methicillin-resistant Staphylococcus aureus nosocomial pneumonia. Chest 124: 1789-1797

37. Fowler VG Jr, Boucher HW, Corey GR, Abrutyn E, Karchmer AW, Rupp ME, Levine DP, Chambers HF, Tally FP, Vigliani GA, Cabell CH, Link AS, DeMeyer I, Filler SG, Zervos M, Cook P, Parsonnet J, Bernstein JM, Price CS, Forrest GN, Fatkenheuer G, Gareca M, Rehm SJ, Brodt HR, Tice A, Cosgrove SE; S. aureus Endocarditis and Bacteremia Study Group (2006) Daptomycin versus standard therapy for bacteremia and endocarditis caused by Staphylococcus aureus. N Engl J Med 355: 653-665 
Table 1A. Methicillin-resistant Staphylococcus aureus (MRSA) vancomycin MIC statistics for city A

\begin{tabular}{|c|c|c|c|c|c|c|}
\hline \multirow[b]{2}{*}{ Year } & \multicolumn{5}{|c|}{ Isolates from city A } & \multirow[b]{2}{*}{$\begin{array}{c}\text { MIC } \geq 1 \mathrm{mg} / \mathrm{L} \\
{[\%]}\end{array}$} \\
\hline & $\begin{array}{l}\text { Number of } \\
\text { strains }\end{array}$ & $\begin{array}{c}\text { Geometric mean } \\
{[\mathrm{mg} / \mathrm{L}]}\end{array}$ & $\begin{array}{c}\text { MIC range } \\
{[\mathrm{mg} / \mathrm{L}]}\end{array}$ & $\begin{array}{l}\mathrm{MIC}_{50} \\
{[\mathrm{mg} / \mathrm{L}]}\end{array}$ & $\begin{array}{l}\mathrm{MIC}_{90} \\
{[\mathrm{mg} / \mathrm{L}]}\end{array}$ & \\
\hline 2004 & 15 & 0.59 & $0.38-1.0$ & 0.5 & 0.75 & 6.67 \\
\hline 2005 & 24 & 0.63 & $0.25-1.0$ & 0.75 & 0.75 & 4.17 \\
\hline 2006 & 30 & 0.56 & $0.38-1.0$ & 0.5 & 0.75 & 3.33 \\
\hline 2007 & 24 & 0.66 & $0.25-1.5$ & 0.75 & 1.0 & 20.83 \\
\hline 2008 & 26 & 0.75 & $0.38-2.0$ & 0.75 & 1.0 & 23.08 \\
\hline 2009 & 14 & 0.79 & $0.5-1.5$ & 0.75 & 1.0 & 35.71 \\
\hline
\end{tabular}

MIC: Minimum inhibitory concentration 
Table 1B. Methicillin-resistant Staphylococcus aureus (MRSA) vancomycin MIC statistics from city B

\begin{tabular}{|c|c|c|c|c|c|c|}
\hline \multicolumn{7}{|c|}{ Isolates from city $B$} \\
\hline Year & $\begin{array}{l}\text { Number of } \\
\text { strains }\end{array}$ & $\begin{array}{c}\text { Geometric mean } \\
{[\mathrm{mg} / \mathrm{L}]}\end{array}$ & $\begin{array}{c}\text { MIC range } \\
{[\mathrm{mg} / \mathrm{L}]}\end{array}$ & $\begin{array}{l}\mathrm{MIC}_{50} \\
{[\mathrm{mg} / \mathbf{L}]}\end{array}$ & $\mathrm{MIC}_{90}$ & $\begin{array}{c}\mathrm{MIC} \geq 1 \mathrm{mg} / \mathrm{L} \\
{[\%]}\end{array}$ \\
\hline 2004 & 29 & 0.47 & $0.25-0.75$ & 0.5 & 0.75 & 0 \\
\hline 2005 & 25 & 0.44 & $0.25-0.75$ & 0.38 & 0.75 & 0 \\
\hline 2006 & 29 & 0.48 & $0.25-1.0$ & 0.5 & 0.75 & 3.45 \\
\hline 2007 & 30 & 0.46 & $0.25-0.75$ & 0.5 & 0.5 & 0 \\
\hline 2008 & 28 & 0.46 & $0.38-0.75$ & 0.5 & 0.5 & 0 \\
\hline 2009 & 13 & 0.51 & $0.38-1.0$ & 0.5 & 0.75 & 7.69 \\
\hline
\end{tabular}

MIC: Minimum inhibitory concentration 
Figure 1A. Vancomycin minimum inhibitory concentration (MIC) trends from city A, 2004-2009

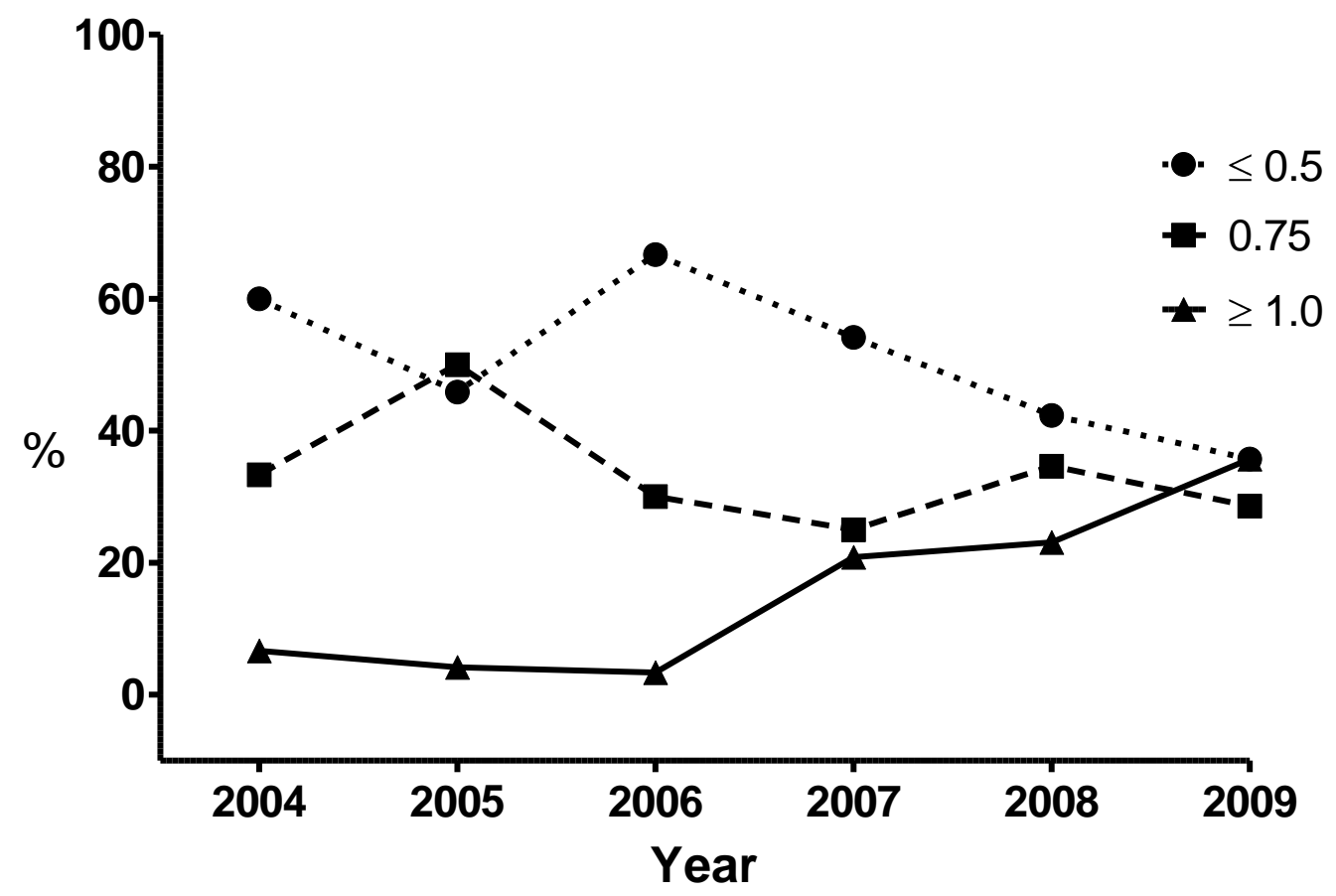


Figure 1B. Vancomycin minimum inhibitory concentration (MIC) trends from city B, 2004-2009

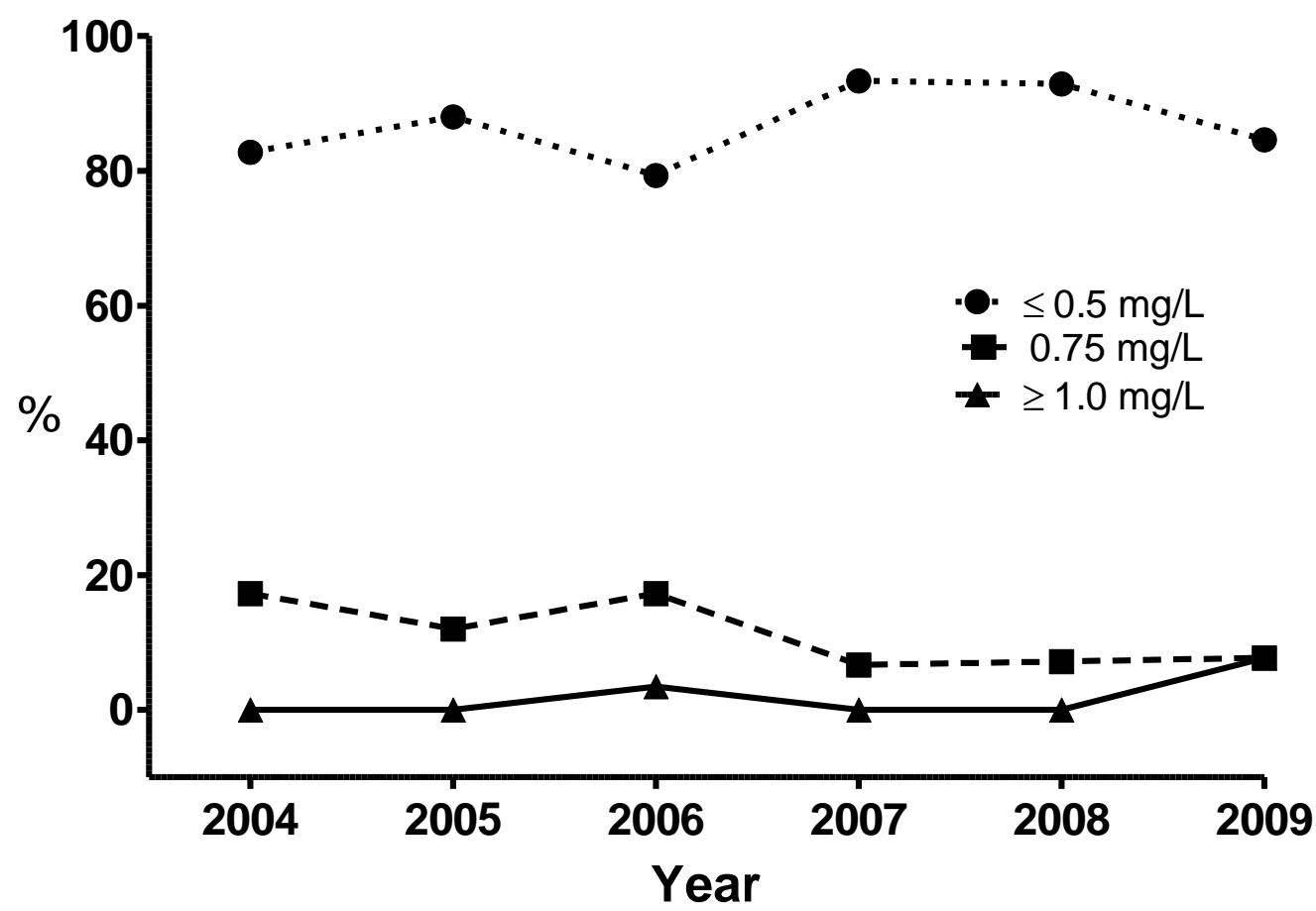


Figure 2. Dendrogram and gel images for methicillin-resistant $S$. aureus (MRSA) creep isolates with vancomycin $\mathrm{MIC} \geq 1 \mathrm{mg} / \mathrm{L}$

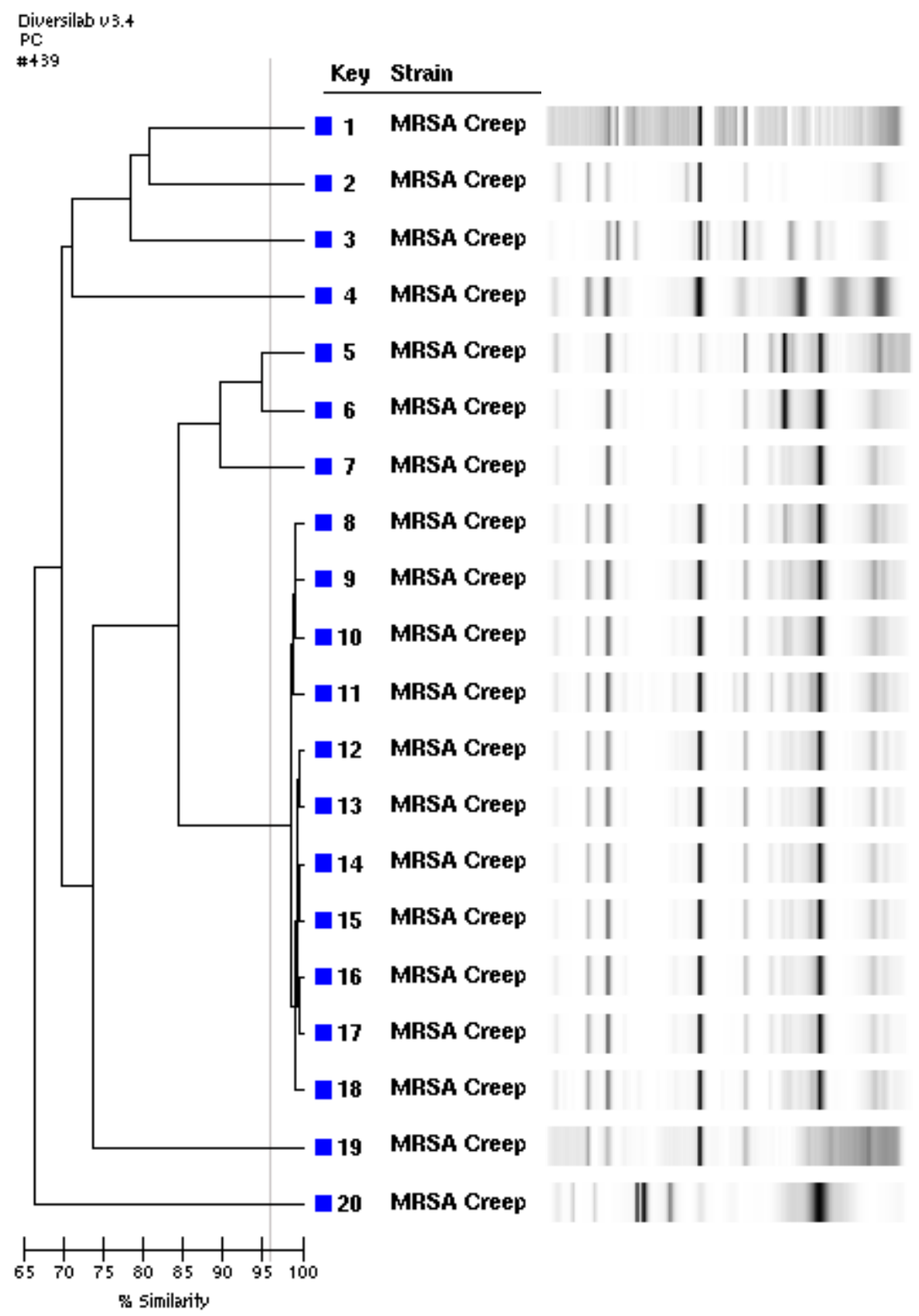

Dendrogram and gel images show clusters of methicillin-resistant S. aureus (MRSA) isolates. The horizontal bar at the bottom left indicates the percent similarity coefficient within the strains. For genotyping, a cut-off of $96 \%$ similarity (vertical line) was defined. 